\title{
Diuretics-assisted treatment of chronic laxative abuse
}

\author{
Yuichi Shirasawa $\cdot$ Michio Fukuda \\ Genjiro Kimura
}

Received: 14 August 2013/Accepted: 11 March 2014/Published online: 26 March 2014

(C) Japanese Society of Nephrology 2014

\begin{abstract}
Hypopotassemia with acid-base imbalance caused by laxative abuse is one of the disorders that nephrologists can be consulted for. Although laxatives are not supposed to form psychological dependence in themselves and their abuse should be cured theoretically by just finishing the overdose, the patients often resist treatment due to unpleasant symptoms such as edema and worsening constipation. Thus, chronic laxative abuse is often regarded as a drug addiction. We report a successfully treated case of chronic laxative abuse, where drastic reduction of laxatives was achieved by applying diuretics. After drastic reduction of laxatives, diuretics were added until they eased edema and bloating so that the patient could feel them to be tolerable, paying attention to lab data such as potassium and renal function. The diuretics, which substituted for laxatives in fluid control, could be tapered off over 3 months without any withdrawal symptoms or a need of additional laxatives. Our experience of simple but successful treatment of chronic laxative abuse emphasizes importance of physical management and suggests that there are cases where the two different kinds of drugs, laxatives and diuretics, can practically be regarded as swappable in the treatment of laxative abuse. This presentation should contribute to accumulation of knowledge in how to treat
\end{abstract}

\footnotetext{
Y. Shirasawa $(\bowtie) \cdot$ M. Fukuda

Department of Cardio-Renal Medicine and Hypertension, Nagoya City University School of Medicine, 1 Kawasumi, Mizuho-Cho, Mizuho Ward, Nagoya City,

Aichi Prefecture 467-8601, Japan

e-mail: yuiville@med.nagoya-cu.ac.jp

G. Kimura

Asahi Rosai Hospital, Japan Labour Health and Welfare Organization, 61 Hirakocho-Kita, Owariasahi City, Aichi Prefecture 488-8585, Japan
}

chronic laxative abuse where no standardized method is established yet.

Keywords Laxative abuse - Senna - Edema - Diuretics . Pseudo-Bartter syndrome

\section{Introduction}

It is well known that laxative abusers often appear with psychiatric problems such as eating disorders [1]. Laxatives, however, do not form psychological dependence in themselves. Indeed, patients withdrawing from laxatives often suffer from physical problems such as persisting edema, weight gain and constipation [2]. Behind these symptoms is strong body fluid retention which can bring about acute heart failure [3], or intestinal edema resulting in ileus in an extreme case [4].

Laxative abuse can cause hypopotassemia with either metabolic acidosis through fecal losses of bicarbonate or metabolic alkalosis related to hypovolemia, similar to pseudo-Bartter syndrome seen in diuretic abuse. No literature, however, was found concerning about swappability of these drugs, laxatives and diuretics, in clinical fluid control. We took notice of this idea in treating laxative abuse, considering that no standard treatment had been established for it and that the treatment can be impeded by strong body fluid retention, which is of renal origin.

\section{Case report}

A 41-year-old woman went to see a local doctor with a medical check-up report suggesting hypopotassemia. She had complaints of persisting constipation and vomiting. 
Table 1 Data before and after treatment

\begin{tabular}{|c|c|c|c|}
\hline & $\begin{array}{l}\text { On } \\
\text { admission }\end{array}$ & $\begin{array}{l}3 \text { months } \\
\text { later }\end{array}$ & \\
\hline \multicolumn{4}{|l|}{ Urinalysis } \\
\hline Specific gravity & 1.010 & 1.020 & \\
\hline $\mathrm{pH}$ & 6.5 & 5.5 & \\
\hline Urine protein & $(1+)$ & $(+-)$ & \\
\hline Urine protein $(\mathrm{mg} / \mathrm{dL})$ & 48 & 11 & \\
\hline Urine protein $(\mathrm{mg} / \mathrm{gCr})$ & 733.6 & 133.1 & \\
\hline Occult blood & $(-)$ & $(-)$ & \\
\hline $\begin{array}{l}\text { Urine } \beta_{2} \text {-microglobulin } \\
\quad(\mathrm{mg} / \mathrm{gCr})\end{array}$ & 25.5 & N/D & \\
\hline Sodium (mEq/L) & $<10$ & 79.7 & \\
\hline Potassium (mEq/L) & 5.4 & 21.9 & \\
\hline Chloride (mEq/L) & 111 & 123.5 & \\
\hline \multicolumn{4}{|l|}{ Complete blood count } \\
\hline White blood cells $(/ \mu \mathrm{L})$ & 9,900 & 7,400 & \\
\hline $\begin{array}{l}\text { Red blood cells }\left(\times 10^{4} /\right. \\
\quad \mu \mathrm{L})\end{array}$ & 510 & 386 & \\
\hline Hemoglobin (g/dL) & 16.5 & 12.4 & \\
\hline Hematocrit (\%) & 45.9 & 39.7 & \\
\hline $\begin{array}{l}\text { Mean corpuscular volume } \\
\text { (fL) }\end{array}$ & 90.0 & 102.8 & \\
\hline Platelets $(/ \mu \mathrm{L})$ & 368,000 & 373,000 & \\
\hline \multicolumn{4}{|l|}{ Blood chemistry } \\
\hline Total proteins $(\mathrm{g} / \mathrm{dL})$ & 6.9 & 6.8 & \\
\hline Albumin (g/dL) & 4.5 & 4.3 & \\
\hline $\begin{array}{l}\text { Aspartate } \\
\text { aminotransferase (U/L) }\end{array}$ & 25 & 16 & \\
\hline $\begin{array}{l}\text { Alanine aminotransferase } \\
\text { (U/L) }\end{array}$ & 25 & 13 & \\
\hline LDH (U/L) & 217 & 208 & \\
\hline $\begin{array}{l}\text { Alkaline phosphatase } \\
\text { (U/L) }\end{array}$ & 241 & 172 & \\
\hline Creatin kinase (U/L) & 161 & $\mathrm{~N} / \mathrm{D}$ & \\
\hline Creatinine (mg/dL) & 1.1 & 0.9 & \\
\hline Uric acid (mg/dL) & 5.4 & 5.7 & \\
\hline Urea nitrogen $(\mathrm{mg} / \mathrm{dL})$ & 5.4 & 23 & \\
\hline Glucose (mg/dL) & 98 & 94 & \\
\hline Total cholesterol (mg/dL) & 232 & 247 & \\
\hline Sodium (mEq/L) & 130 & 146 & \\
\hline Potassium (mEq/L) & 2.5 & 4 & \\
\hline Chloride (mEq/L) & 96 & 108 & \\
\hline Magnesium (mg/dL) & 2.8 & 2.3 & \\
\hline Calcium (mg/dL) & 8.8 & 9.6 & \\
\hline Phosphate (mg/dL) & 3.6 & 4.6 & \\
\hline \multicolumn{4}{|l|}{ Endocrinology } \\
\hline $\begin{array}{l}\text { Thyroid-stimulating } \\
\text { hormone (IU/mL) }\end{array}$ & 2.66 & 2.60 & $(0.292-3.080)$ \\
\hline Free $T_{4}(n g / d L)$ & 1.6 & 0.90 & $(0.66-1.20)$ \\
\hline Free $\mathrm{T}_{3}(\mathrm{pg} / \mathrm{mL})$ & 2.22 & 2.69 & $(2.50-3.69)$ \\
\hline
\end{tabular}

Table 1 continued

\begin{tabular}{|c|c|c|c|}
\hline & $\begin{array}{l}\text { On } \\
\text { admission }\end{array}$ & $\begin{array}{l}3 \text { months } \\
\text { later }\end{array}$ & \\
\hline $\begin{array}{l}\text { Plasma renin activity } \\
(\mathrm{ng} / \mathrm{mL} / \mathrm{h})\end{array}$ & 110 & N/D & \\
\hline Aldosterone (pg/mL) & 582 & N/D & $(35.7-240)$ \\
\hline \multicolumn{4}{|l|}{ Arterial blood gas } \\
\hline $\mathrm{pH}$ & 7.33 & 7.35 & \\
\hline $\mathrm{PCO}_{2}$ (Torr) & 34.3 & 42.4 & \\
\hline $\mathrm{PO}_{2}$ (Torr) & 179.7 & 100.7 & \\
\hline $\mathrm{HCO}_{3}{ }^{-}(\mathrm{mEq} / \mathrm{L})$ & 17.9 & 23.3 & \\
\hline
\end{tabular}

$N / D$ no data

She looked extraordinary thin to the doctor so that he suspected that she should have been suffering from anorexia nervosa. Finding some casts in urine sediments, he introduced her to our division of nephrology for further examination and treatment, recommending consultation with a psychiatrist.

It was revealed that she had been using 50 tablets ( $264 \mathrm{mg}$ sennoside A and B as major components) of over-the-counter (OTC) laxatives per night for years to overcome her "obstinate" constipation. Her body temperature was $36.8{ }^{\circ} \mathrm{C}$, blood pressure $98 / 70 \mathrm{mmHg}$ and pulse rate 64 beats $/ \mathrm{min}$. The body mass index was only 14.3 (body height $156 \mathrm{~cm}$, body weight $34.8 \mathrm{~kg}$ ). Despite the complaint of chronic constipation, physical examination proved no apparent problem in the abdomen. Bowel sounds were normal to slightly frequent. Blood tests revealed abnormal values, which were mostly explainable with laxative abuse, possible eating disorders and resulting chronic dehydration: hypopotassemia, mild hypermagnesemia, decreased renal function, metabolic acidosis with respiratory compensation, low $\mathrm{T}_{3}$, increased plasma renin activity, etc. (Table 1).

Focusing on correction but not discontinuation of laxatives, we hospitalized her, stopped all the OTC drugs with her and started to give her rather small amount of sennoside- one tablet $(12 \mathrm{mg}$ ) per day on the day on admission (defined as day 0 ), which produced no defecation on the next day (day 1), then was increased up to 3 tablets $(36 \mathrm{mg})$ per day by consent. Although X-ray photos also indicated that bowel movements were not impaired despite of hypopotassemia, hypopotassemia was targeted for correction at the same time, considering of the abnormal electrocardiogram with negative $\mathrm{T}$ waves and appearance of $\mathrm{U}$ waves. Strict salt intake restriction $(\mathrm{NaCl} 5 \mathrm{~g} /$ day) was put into practice 7 days after hospitalization at last, when she stopped eating outside of the hospital. The reason why she had been admitted to go out until then was that we 

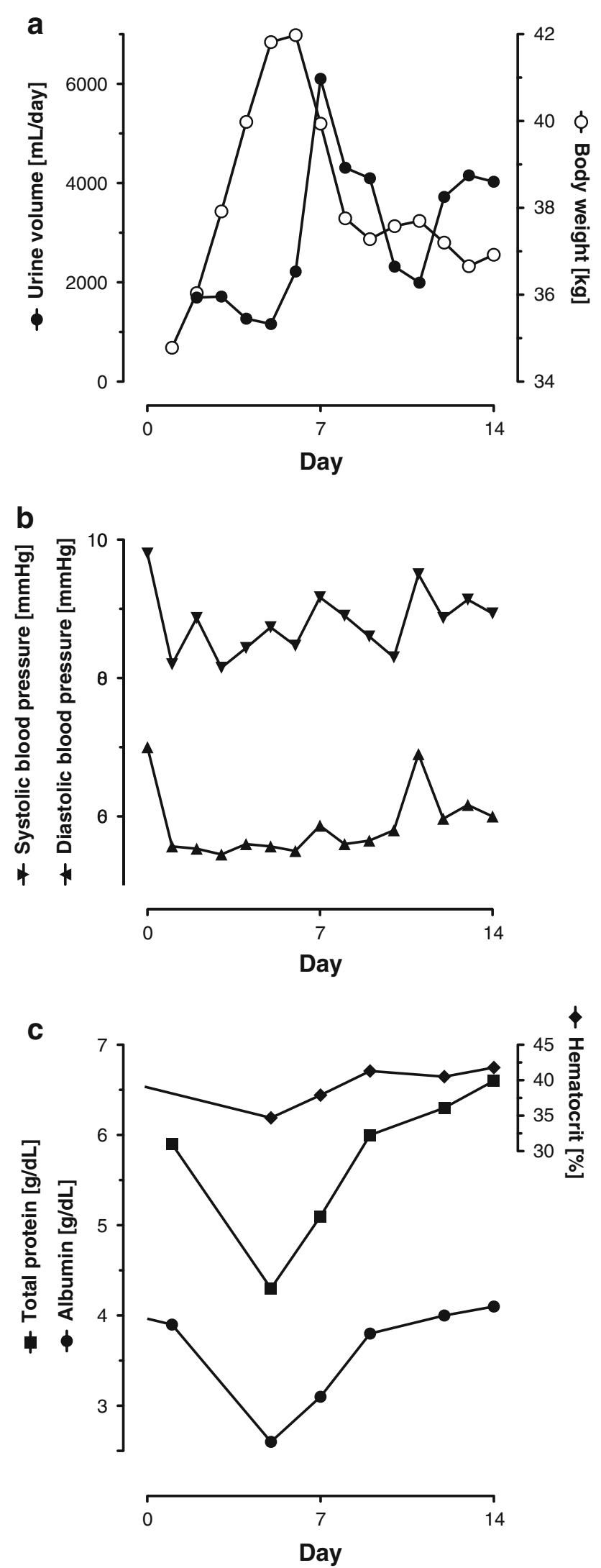

Fig. 1 Temporal relationships of body weight and urine volume (a), blood pressure (b), and hematocrit and total protein and albumin levels (c) during the hospitalization had accepted her claim that she would need to use her home shower due to her fastidiousness about cleanliness. Much more attention should have been paid to her eating habit to control her salt and water intake.

In the first week of hospitalization, urine volume kept around 1-2 L/day (Fig. 1a) and fluctuation of blood pressure did not seem to be clinically significant (Fig. 1b). Her body weight, however, began to increase by $1-2 \mathrm{~kg} /$ day (Fig. 1a) and bloating and strong edema in the face and extremities emerged, which she said was what she had been afraid of. Although hypoproteinemia seemed to emerge as a result of cancellation of hemoconcentration and following hemodilution, it transiently reached a level that could contribute to edema (Fig. 1c).

The strong fluid retention was to be controlled. Having found no proper guidelines to the situation, we decided not to increase the dose of laxatives but to alternatively add diuretics until she could feel the symptoms as tolerable. In fact, the amount of sennoside before treatment was equivalent to that of 22 tablets we prescribe in hospital, which was not realistic even if we could reduce some from that. Despite hyperreninemia and hyperaldosteronemia (Table 1), suppressed urine potassium excretion and negative urine anion gap meant that kidney was working against extrarenal cause of hypopotassemia (Table 1; Fig. 2). Trans-tubular potassium gradient, defined as: (plasma osmolality $\times$ urine potassium)/(plasma potassium/ urine osmolality), was only 1.96 , though it was unsure that this index could reflect the aldosterone effect on renal potassium excretion in such a chronic situation. To control the acute and strong body fluid retention, we chose loop diuretics because they are fast and strong, therefore, easy to adjust especially in controlling an acute phase of body fluid excess. Although we chose them considering their possible effects on hypopotassemia, the usage was almost trial and error. The unsophisticated way was depicted honestly in Fig. 4. A potassium-sparing loop diuretic, torasemide, was adopted at first to minimize worsening of hypopotassemia. Azosemide was combined because we expected that torasemide alone would not be effective enough. This combination did not reduce the body weight in day 5-6, though the urine volume appeared to be slightly responsive (Fig. 1a). So we switched to furosemide from these in day 6 , which lead to marked increase of urination and decrease of body weight in day 6-7 (Fig. 1a). Blood test, repeated every 2-3 days to check electrolytes and else, revealed that the hypopotassemia started to be resolved around day 5 (Fig. 3a). Serum chloride level transiently decreased comparing to that of sodium during the polyuria (Fig. 3b). After breaking away the acute condition where we cared the strong and rapid body fluid retention mainly with loop diuretics, diuretics were adjusted: We started spironolactone on day 8 and switched furosemide back to azosemide 


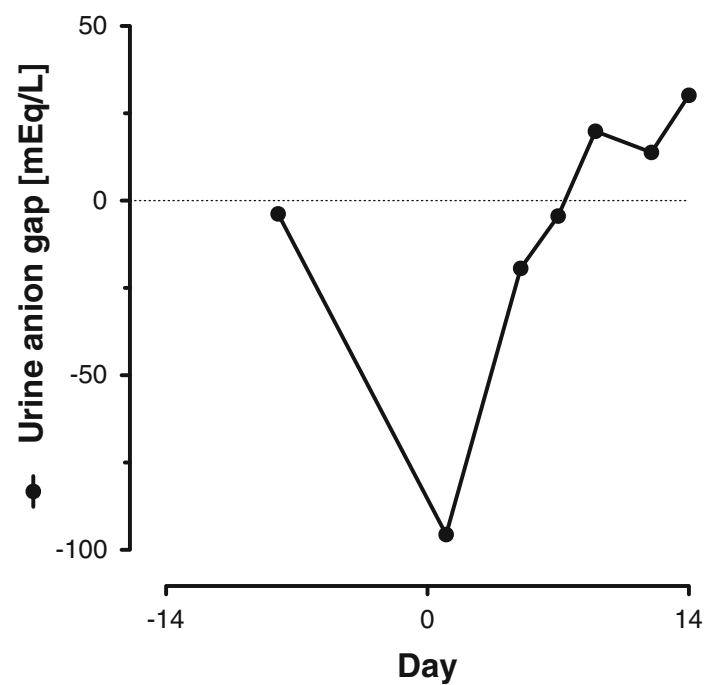

Fig. 2 The urine anion gap, calculated as $\left[\mathrm{Na}^{+}\right]+\left[\mathrm{K}^{+}\right]-\left[\mathrm{Cl}^{-}\right]$

on day 11. After 14 days of hospitalization, her body weight increased by $2.1 \mathrm{~kg}$, the serum creatinine decreased from $1.1-1.2$ to $0.9 \mathrm{mg} / \mathrm{dL}$. Transiently plunged hematocrit and albumin levels both recovered in parallel to about the same levels before treatment (Fig. 1c).

The diuretics were gradually decreased over 3 months in our outpatient department, paying attention to electrolytes and acid-base balance. Usage of the diuretics was summarized in Fig. 4. What she needed for acceptable defecation after all was just 2-3 tablets of sennoside and occasional use of a baking soda suppository. Data before she was returned to the former local doctor are also shown in the Table 1. While being followed up there for 3 years, she repeated laxative abuse once and reintroduced to us, with another elevation of serum creatinine level from 0.9 to $1.7 \mathrm{mg} / \mathrm{dL}$. She could be free from laxative abuse soon and left us again, when the renal function had not fully recovered $(\mathrm{Cr} \sim 1.4 \mathrm{mg} / \mathrm{dL})$. After discharged, no significant urine sediment nor electrocardiogram abnormality has been pointed out in her medical checkup to date.

\section{Discussion}

There are chances for nephrologists to see patients with laxative and/or diuretic abuse, because cases of mineral disorders, especially potassium, can often be introduced to them. Depending on the effect on intestinal bicarbonate loss, impaired acid-base balance can be either acidosis or alkalosis. Although urine acidification can be impaired in severe volume depletion [5], it was supposed in the present case that kidneys kept excreting acids as was shown by negative urine anion gap in the first week of hospitalization (Fig. 2). The main reason that the urine $\mathrm{pH}$ did not lower so
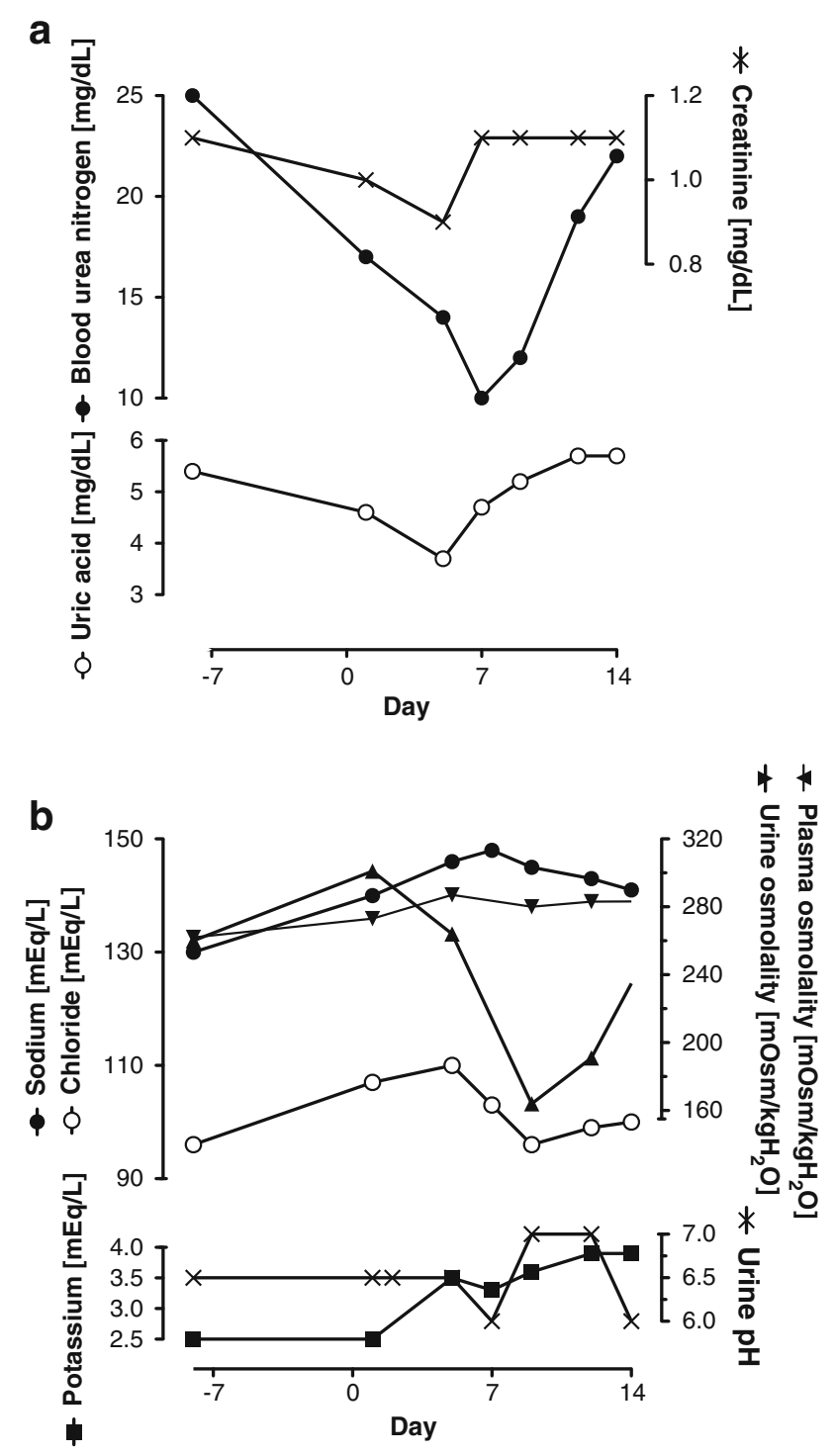

Fig. 3 Temporal relationships of blood urea nitrogen, uric acid, and serum creatinine levels (a), concentrations of serum sodium, chloride, and potassium, osmolalities of plasma and urine, and urine $\mathrm{pH}(\mathbf{b})$

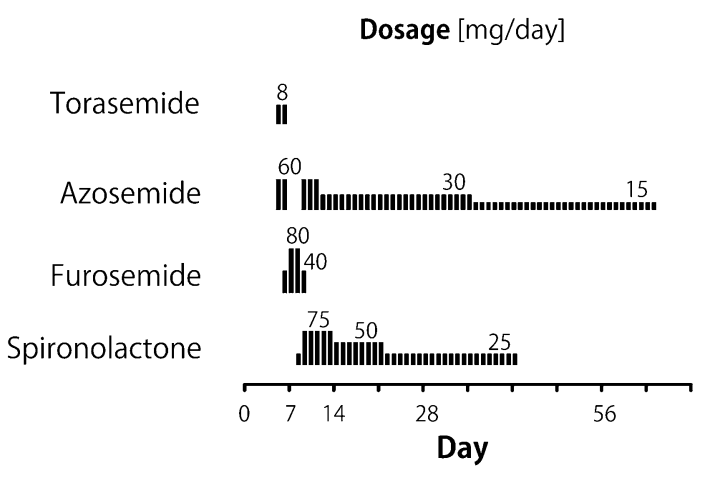

Fig. 4 Temporal relationships of diuretics used in the treatment, daily doses expressed in numbers ( $\mathrm{mg} /$ day) 
much was supposed to be that the proton was buffered with enough-produced ammonium. Urine with specific gravity 1.010 on admission was relatively diluted in usual situations, which is empirically supposed to be around $350 \mathrm{mOsm} / \mathrm{kg} \mathrm{H}_{2} \mathrm{O}$. This urine specific gravity, actually, meant impaired dilution in the condition, considering the hyponatremia and hypoosmolemia $(273 \mathrm{mOsm} / \mathrm{kg})$ at that time. Although this case, with apparent hypovolemia, differs from typical SIADH, there should have been similar excessive drinking behavior under hypovolemia. This speculation can explain remarkable body weight gain after restriction of laxative abuse (Fig. 1a). The abnormal relationship between urine and plasma osmolality got normalized while hypovolemia was being resolved, resulting in obvious hypotonic uresis. The urine $\mathrm{pH}$ and osmolality transitions are graphed in Fig. 3b.

The treatment of laxative and/or diuretic abuse should be just simply quitting the causative drugs. In most cases, however, it faces difficulty due to physical symptoms such as weight gain, edema and constipation. The body fluid expansion during escaping from the abused drugs is supposed to be due to renal retention, even when the renal function itself is not impaired. Rehydration must be carefully accomplished in cases of "pseudo-idiopathic edema" [6] due to laxative abuse and their wearing off. Once overhydration occurs like the present case, diuretics may be carefully used as necessary. In general, diuretics should be avoided in hypovolemic conditions. They were started in this case when hydration was supposed to be recovered and perfect control of extra body fluid was not pursued. Actually, we were far from suppressing hypervolemia. The fluid retention was so strong that the body weight increased by 20.7 or $13.6 \%$ in maximum, compared to that on admission or on discharge, respectively (Fig. 1a). A similar case has been reported where strong body fluid retention occurred upon quitting abused laxatives, resulting in acute heart failure requiring furosemide to control [3]. Although the fast and strong effects of loop diuretics were preferable in controlling an acute phase of body fluid excess, we do not deny that spironolactone should have been one of the first to choose pathophysiologically, and that loop diuretics should be used secondarily. The low TTKG might have simply reflected potassium depletion in such a chronic state. Considering that hypopotassemia can suppress secretion of aldosterone, interpreted to serve as a protective feedback mechanism against worsening of potassium disorder, it could be about another timing for starting spironolactone when hypopotassemia was dissolved. There may be another idea to use an angiotensin-converting enzyme inhibitor targeting at the activated renin-angiotensin system [3]. It should be kept in mind, however, that laxative abusers are generally hypovolemic and hypotensive at least at first, as seen in the present case where no hypertension was observed throughout the course. One of the reasons we believe that the treatment was successful is that the basic tactics, swapping causative drugs from laxatives to diuretics, was so simple itself that the patient could easily accept. Although it may have been practiced previously, intentionally or unintentionally, documentation of diuretic application purposed for escaping from laxative abuse could not be found. While pharmacologically categorized as a stimulant laxative, sennoside in high dose is reported to induce a net secretion of $\mathrm{Na}^{+}$and $\mathrm{H}_{2} \mathrm{O}$, where the paracellular secretion occurs electrochemically and osmotically due to increased permeability of small molecules in colon mucosa of rat $[7$, 8]. This may hint that high-dose laxatives can suppress body fluid just as diuretics, indeed. There may be other reasons on the patient side. Different from similar patients with eating disorders, she complained of vomiting, not hiding it that is often self-induced. This may suggest that discomfort of nausea was so intolerable, or that her personality problem was not so serious, if any. She might have noticed that watery defecation had become necessary to suppress edema. Anyway, she did not have self-harm other than laxative abuse at least before us and seemed cooperative enough and ready for treatment when she came to us. Doctors should not prescribe diuretics to patients with idiopathic edema, who can sometimes have a characteristic problem similar to eating disorders [6]. It should be noted that such patients often extend to laxatives, available as OTC drugs in Japan, and that certain diuretics may be obtained via the Internet without prescription these days.

We reported a successfully treated case of chronic laxative abuse, where drastic reduction of laxatives was achieved by applying diuretics. It is hoped that our experience will be beneficial to other physicians and psychiatrists in treating patients of chronic laxative abuse and finding a more generalized way of its treatment.

Conflict of interest All the authors have declared no competing interest.

\section{References}

1. Tozzi F, Thornton LM, Mitchell J, Fichter MM, Klump KL, Lilenfeld LR, Reba L, Strober M, Kaye WH, Bulik CM. Features associated with laxative abuse in individuals with eating disorders. Psychosom Med. 2006;68:470-7.

2. Meyers AM, Feldman C, Sonnekus MI, Ninin DT, Margolius LP, Whalley NA. Chronic laxative abusers with pseudo-idiopathic oedema and autonomous pseudo-Bartter's syndrome. a spectrum of metabolic madness, or new lights on an old disease? S Afr Med J. 1990;78:631-6.

3. Riley JA, Brown AR, Walker BE. Congestive cardiac failure following laxative withdrawal. Postgrad Med J. 1996;72:491-2.

4. Yokoyama S, Koide Y, Washizuka T, Kitahara A, Takahashi T, Amano N. Jpn J Gen Hosp Psychiatry. 2002;14:194-9 (Article in Japanese). 
5. Batlle DC, von Riotte A, Schlueter W. Urinary sodium in the evaluation of hyperchloremic metabolic acidosis. N Engl J Med. 1987;316:140-4.

6. Korzets Z, Hasdan G, Podjarny E, Bernheim J. Excessive fluid gain in a chronic laxative abuser: "pseudo-idiopathic" oedema. Nephrol Dial Transplant. 2002;17:161-2.
7. Leng-Peschlow E. Sennoside-induced secretion is not caused by changes in mucosal permeability or $\mathrm{Na}+, \mathrm{K}(+)$-ATPase activity. J Pharm Pharmacol. 1993;45:951-4.

8. Leng-Peschlow E. Sennoside-induced secretion and its relevance for the laxative effect. Pharmacology. 1993;47(Suppl 1):14-21. 